\title{
A Decade of Software Engineering Best Practices Adoption in Small Companies: A Quasi-Systematic Mapping
}

\author{
Alex Costa \\ Department of Exact Sciences \\ Juliana Saraiva \\ Department of Exact Sciences \\ Yuska P. C. Aguiar \\ Federal University Federal of Paraiba Federal University Federal of Paraiba Federal University Federal of Paraiba \\ Rio Tinto - PB, Brazil \\ Rio Tinto - PB, Brazil \\ alex.costa@dcx.ufpb.br \\ julianajags@dcx.ufpb.br \\ Rio Tinto - PB, Brazil \\ yuska@dcx.ufpb.br
}

\begin{abstract}
SWEBOK is a guideline that provides information about Software Engineering (SE) knowledge, including a list of Best Practices (BPs) for adopting. However, small companies have restrictions such as, limited budget, reduced schedule, and, small staff that can hinder the advantages of these BPs adoption. Thus, this paper investigated the last decade of BPs adoption reported by small companies' environment. A quasi-systematic mapping was conducted for assessing studies that addressed this issue, and it was possible to observe that the most prominent BPs adopted are "test application" and "software process model adoption". On the other hand, "limited budget" and "staff size" were found as causes for non-adoption of SWEBOK's BPs.
\end{abstract}

\section{CCS Concepts}

- Information Software and its engineering $\rightarrow$ Software creation and management $\rightarrow$ Software development techniques

\section{Keywords}

Software Engineering; SWEBOK's; small companies; best practice.

\section{INTRODUCTION}

A widely used guide on Software Engineering (SE) is the SWEBOK (Software Engineering Body of Knowledge) [18]. It is a project for supporting many organizations to build a consensus on the core body of SE knowledge. According to the SWEBOK, best practices can include the following activities: peer-to-peer review, testing, risk mitigation, knowledge management, reuse practices, among others [17] [18]. The adoption of these practices can improve business performance and productivity, and decrease project costs/budget. Consequently, the practices' adoption reflects on the product quality level, customer satisfaction, and financial returning - aspects that contribute for increasing company competitiveness [6].

Based on that, the best practices' adoption can be hindered in small companies by the informality during the software development process. Sometimes, it occurs because of the economic hardship faced by these companies [9] [12] [19]. In addition, the context of

Permission to make digital or hard copies of all or part of this work for personal or classroom use is granted without fee provided that copies are not made or distributed for profit or commercial advantage and that copies bear this notice and the full citation on the first page. To copy otherwise, or republish, to post on servers or to redistribute to lists, requires prior specific permission and/or a fee.

SBSI 2017, June $5^{\text {th }}-8^{\text {th }}, 2017$, Lavras, Minas Gerais, Brazil.

Copyright SBC 2017. simple communication, unstable processes, deployment quickly demanded, and inexperience in applying software engineering concepts can be highlighted as difficulties during the best practices adoption [7]. Complementarily, new technologies and process approaches have been improving, making harder the staff training forcing companies to deal with small budget and short deadlines.

Therefore, it is clear the necessity of understanding how small software development companies have been accessing information of software engineering best practices, and how they are applying day-by-day on the last decade. We believe that the spreading reports by small companies can motivate other companies that see the best practices adoption with skeptism. In addition, this information can make easier the decision-making process about which practices could be adopted, at least, in a particular software project/scenario of small companies.

In this context, the research problem addressed in this work is the lack of useful information about the software engineering best practices adopted in small companies. The following Research Questions (RQs) guide the study conducting:

- RQ01: What are the software engineering best practices adopted in small companies?

- RQ02: What are the software engineering best practices defined by SWEBOK Guide that have been (or not) followed by the small companies?

- RQ03: What are the reasons of the non-adoption of the software engineering best practices in small companies?

Thus, this study aims at mapping the software engineering best practices adopted by small companies, compare the results with the SWEBOK Guide standardization, and report what have been done during the last decade in this industrial environment, at least that one reported in academic resources. The following specific goals were raised targeting the main goal: (i) to list the software engineering best practices by the most recent publication of SWEBOK; (ii) to list the software engineering best practices used by small companies; (iii) to list the software engineering best practices that are not used by small companies; and (iv) to identify the reasons why the small companies do not use some of best practices.

This paper is organized as follow: in Section 2, the methodology is presented. In Section 3, the results achieved by the research are discussed. The limitations and the threats to validity are depicted in Section 4, and finally, the conclusions and future work are shown in Section 5. 


\section{METHODOLOGY}

The research conducted in this work is characterized as a theoretical exploration from the literature. The searching relied on a systematic mapping protocol, and the assessment of the resultant data was performed in quantitative and qualitative way. According to Petersen and contributors [16], a systematic mapping is a method for constructing a classification scheme and structure of a field in the interest area [14]. Its methodological procedure includes: the goal definition, the systematic mapping protocol building, primary studies selection, data extraction, and analysis of resultant data. It means that mapping studies try to gather all research related to a specific topic. Questions are broader and more general when they are compared with the ones found in Systematic Literature Reviews (SLRs) [7] [8].

In a quasi-systematic mapping studies, human resources and time are limited, reflecting on the amount of primary studies selected and on the number of participants during its execution. In our case, a quasi-systematic mapping is justified by the conditions of the study, particularly regarding the participants available (1 student and 2 professors) and the time for its execution ( 3 months). The following subsections present the methodological steps of the research protocol that is completely available at the research website ${ }^{1}$.

\subsection{Methodology Steps}

The research was composed of 6 steps that are depicted in Figure 1. It is important to highlight that the first step, in which deals with bibliographical study is not part of the mapping protocol, specifically:

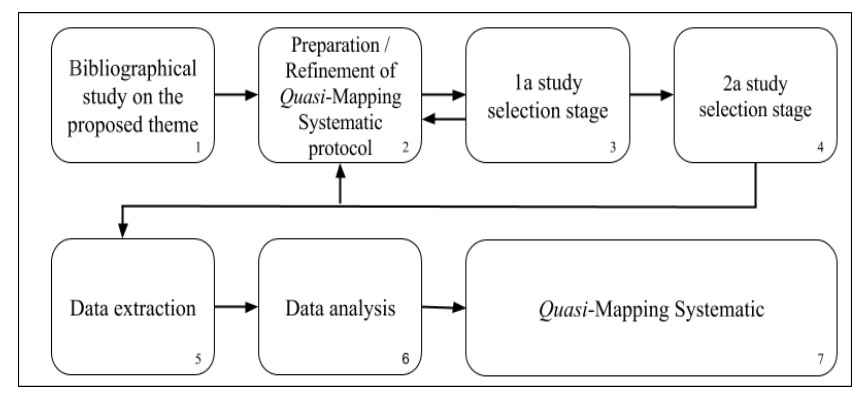

Figure 1. Research methodological steps.

\subsection{Mapping Data Source and Search String}

The search strategy encompasses well-known digital library search engines (data sources). They were chosen based on the relevance for the Computer Science Community and availability for papers downloading:

\section{- IEEE: http://ieeexplore.ieee.org}

- ACM: $\underline{\text { http://dl.acm.org }}$

- SCIENCE DIRECT: $\underline{\text { http://www.sciencedirect.com }}$

- SPRINGER LINK: http://link.springer.com/

- WILEY: http://onlinelibrary.wiley.com/

The search string was set up to be used with similar semantic meaning in all the search engines selected. It is important to clarify that the string was refined and validated with experts. The list below shows the search strings after the refinement in each engine accessed, according by their syntax way for the 'research string' including.

- IEEE: $(+$ practice + AND +"Software engineering" + AND +"small company" +OR +"small companies" +OR +"small teams");

- $\quad$ ACM: (+practice +AND +"Software engineering" +AND +"small company" +OR +"small companies" +OR +"small teams");

- SCIENCE DIRECT: practice AND "software engineering" AND ("small company" OR "small companies" OR "small teams");

- SPRINGER LINK: practice AND "software engineering" AND ("small company" OR "small companies" OR "small teams");

- WILEY: practice in All Fields AND "Software engineering" in All Fields AND "small company" OR "small companies" OR "small teams" in All Fields.

\subsection{Primary Studies Search Strategies}

This section describes the search strategy to select the primary studies. An ID was named for each paper, which is a unique identifier for each study (I.e.: P001 - First Paper selected). The selection of primary studies was conducted in four phases that are described below:

1. Selection of potentially relevant primary studies: reading title, keywords, and abstract.

2. First selection against to exclusion criteria.

3. Conflicts discussion

4. Final selection

Initially (1), only the title, keywords and abstract were taken into account for paper inclusion. It is important to stress that only papers that were clearly out of scope were excluded in this selection. For this phase, the following Inclusion Criteria (IC) were taken into account:

- IC01 - Studies dealing with the practices of software development processes in small companies, projects, or small teams.

- IC02 - Papers published from 2006 to 2016 (for checking the decade of practice).

- $\quad$ IC03 - Studies are full papers (minimum 7 pages).

- $\quad$ IC04 - Papers accessed by web (on digital libraries signed by university where the research was conducted).

On the second phase (2), the Exclusion Criteria (EC) were used to keep only the papers that contain information for answering at least one RQ previously raised. During this phase, the paper was read completely. The following ECs were used:

- $\quad$ EC01 - Duplicate publications.

- EC02 - Study that does not deal with small companies, projects, or small teams.

\footnotetext{
${ }^{1}$ https://goo.gl/vX6dE2
} 
- $\quad$ EC03 - Study that do not contain best practices of SE.

- EC04 - Secondary studies such as, literature review or systematic mapping were excluded.

It is important to clarify that the first and second selections were performed only by the student, however under the advisors' (2 assistant professors) supervision. Nevertheless, the three authors of this paper performed the conflicts discussion (the final phase of papers selection). A conflict resolution meeting was organized and the disagreements discussed. In this final phase (3) each researcher read the full paper. After this meeting, the final set of selected primary studies was composed.

\subsection{Extraction and Data Analysis}

After the final selection, the student read again the whole papers trying to extract the following information form them:

- Authors: Identify the names of the studies' authors

- Year: Publication Year

- Publication Type: Conference or journal or newsletter

- Best Practices: Software engineering practices adopted by small companies, projects, or small teams.

- Process Model: Software Development models adopted in small companies, projects, or small teams.

\section{RESULT DISCUSSION}

This section discusses the results found. Section 3.1 presented an overview of the mapping study, and the answers of the RQ previously raised are depicted in Section 3.2.

\subsection{Mapping Study Overview}

The selection process occurred between 12/02/2016 and 14/04/2016. The results are shown in Table 1 . The first column represents the search engine identification; the second column shows the number of studies listed by each engine. The third and fourth columns indicate the number of studies that remained after the end of each selection phases.

Table 1. Result of studies selection

\begin{tabular}{|l|c|c|c|}
\hline \multicolumn{1}{|c|}{ Search Engine } & $\begin{array}{c}\text { Studies } \\
\text { Listed }\end{array}$ & $\begin{array}{c}\mathbf{1}^{\text {st }} \\
\text { Selection }\end{array}$ & $\begin{array}{c}\mathbf{2}^{\text {nd }} \\
\text { Selection }\end{array}$ \\
\hline IEEE & 232 & 5 & 3 \\
\hline ACM & 435 & 1 & 1 \\
\hline $\begin{array}{l}\text { SCIENCE } \\
\text { DIRECT }\end{array}$ & 195 & 4 & 0 \\
\hline $\begin{array}{l}\text { SPRINGER } \\
\text { LINK }\end{array}$ & 293 & 5 & 2 \\
\hline WILEY & $\mathbf{1 3 4 9}$ & $\mathbf{1 8}$ & $\mathbf{9}$ \\
\hline TOTAL & 194 & 3 & 3 \\
\hline
\end{tabular}

Table 2. Studies Selected

\begin{tabular}{|l|l|l|}
\hline Id & Title & Year \\
\hline
\end{tabular}

\begin{tabular}{|c|c|c|}
\hline P001 & $\begin{array}{l}\text { Selection of good practices for small software } \\
\text { development teams: a knowledge-based } \\
\text { approach [2] }\end{array}$ & 2013 \\
\hline P002 & $\begin{array}{l}\text { Practical Experience in Customization of a } \\
\text { Software Development Process for Small } \\
\text { Companies Based on RUP Processes and MSF } \\
\text { [3] }\end{array}$ & 2007 \\
\hline P004 & $\begin{array}{l}\text { A reduced set of RUP roles to small software } \\
\text { development teams [11] }\end{array}$ & 2012 \\
\hline P005 & $\begin{array}{l}\text { Software Process Practices in Small Software } \\
\text { Companies in Botswana [1] }\end{array}$ & 2014 \\
\hline P011 & $\begin{array}{l}\text { Understanding the gap between software } \\
\text { process practices and actual practice in very } \\
\text { small companies }[15]\end{array}$ & 2016 \\
\hline P012 & $\begin{array}{l}\text { Software SMEs' unofficial readiness for } \\
\text { CMMI®-based software process improvement } \\
{[5]}\end{array}$ & 2015 \\
\hline P013 & $\begin{array}{l}\text { Challenges and industry practices for } \\
\text { managing software variability in small and } \\
\text { medium sized enterprises [4] }\end{array}$ & 2014 \\
\hline P015 & $\begin{array}{l}\text { Investigating the role of CMMI with } \\
\text { expanding company size for small- to medium- } \\
\text { sized enterprises [10] }\end{array}$ & 2010 \\
\hline P017 & $\begin{array}{l}\text { An exploratory study of software process } \\
\text { improvement implementation risks [13] }\end{array}$ & 2012 \\
\hline
\end{tabular}

Table 2 depicts the studies selected. The first column indicates the paper ID, the second column indicates the paper title, and the last column refers to year of study publication.

\subsection{Answering the RQs}

After the selection process, the information extraction was performed for answering the RQs aforementioned. The RQs are following discussed:

RQ01: What are the best software engineering practices adopted in small companies? 


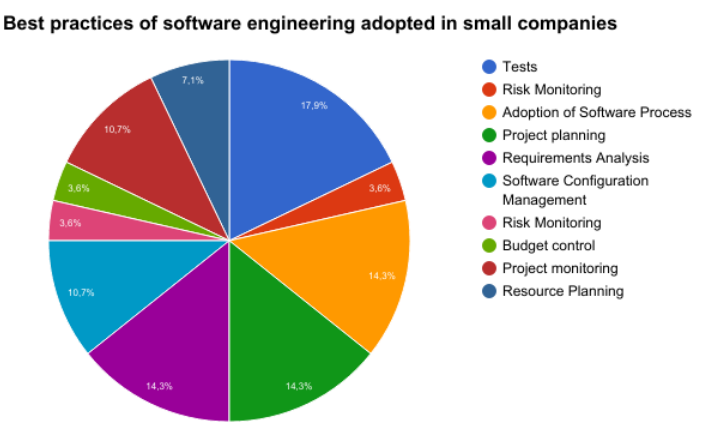

Figure 2. Best practices of software engineering adopted in small companies.

Figure 2 depicts Best Practices (BP) mentioned in the primary studies and that were found in the Guide SWEBOK. 27 BP were shown in SWEBOK Guide, and 10 out of this 27 were cited in the studies selected. The figure informs the percentage of it BP were mentioned by the studies. Table 3 presents the list of BP proposed by SWEBOK and that were found in each study selected. The first column indicates the BP identification, the second column indicates the name of the BP, and the last column shows the papers that mentioned the BP.

It is possible to note the "Application of Tests" is the most prominent BP adopted in small companies. It can evidence the importance of test, and the truth of the statement: it is impossible to deploy a software system without test, independently of the company size. On second place, the "Adoption of any kind of process model", "project planning", and "requirement analysis" are relevant BPs to be adopted by small companies. Consequently, it is notary that the small companies adopt a process model even that occur any adaption. This process guides the companies in the decision-making process about which BPs should be mandatorily chosen. It seems that is also occurs with BP003 (Project planning) and BP004 (Requirements Analysis), minimally.

Table 3. Best Practices adopted in Small Companies

\begin{tabular}{|l|l|l|}
\hline ID & SWEBOK BP & Study ID \\
\hline BP001 & Tests & $\begin{array}{l}\text { P011, P013, P012, } \\
\text { P015, P017 }\end{array}$ \\
\hline BP012 & Adoption of Software Process & $\begin{array}{l}\text { P002, P011, P012, } \\
\text { P013 }\end{array}$ \\
\hline BP003 & Project planning & $\begin{array}{l}\text { P001, P004, P005, } \\
\text { P015 }\end{array}$ \\
\hline BP004 & Requirements Analysis & $\begin{array}{l}\text { P001, P004, P005, } \\
\text { P015 }\end{array}$ \\
\hline BP005 & $\begin{array}{l}\text { Software Configuration } \\
\text { Management }\end{array}$ & P004, P005, P015 \\
\hline
\end{tabular}

\begin{tabular}{|c|c|c|}
\hline ВР006 & Project monitoring & P001, P004, P015 \\
\hline ВР007 & Resource Planning & P001, P004 \\
\hline ВР008 & Risk Monitoring & P015 \\
\hline ВР009 & Software Construction & P001 \\
\hline ВР010 & Budget control & P001 \\
\hline ВР011 & $\begin{array}{l}\text { Designing the user interface } \\
\text { design }\end{array}$ & - \\
\hline ВР012 & $\begin{array}{l}\text { Design activities Quality } \\
\text { Analysis and Evaluation }\end{array}$ & - \\
\hline ВР013 & $\begin{array}{l}\text { Design Structure and Software } \\
\text { Architecture }\end{array}$ & - \\
\hline ВР014 & $\begin{array}{l}\text { Design Notations, Strategies } \\
\text { and Methods }\end{array}$ & - \\
\hline ВP015 & Maintenance Planning & - \\
\hline ВР016 & $\begin{array}{l}\text { Software Configuration } \\
\text { Management }\end{array}$ & - \\
\hline ВР017 & $\begin{array}{l}\text { Activities forms of project } \\
\text { documentation generation }\end{array}$ & - \\
\hline ВР018 & Design Reuse & - \\
\hline ВР019 & Software Construction Project & - \\
\hline ВР020 & Quality and Integration & - \\
\hline ВР021 & $\begin{array}{l}\text { Software Quality } \\
\text { Requirements }\end{array}$ & - \\
\hline ВР022 & $\begin{array}{l}\text { Technical SCM - (Software } \\
\text { Quality Management) }\end{array}$ & - \\
\hline ВР023 & $\begin{array}{l}\text { Measurement of Software } \\
\text { Quality }\end{array}$ & - \\
\hline ВР024 & Software Process Assessment & - \\
\hline ВР025 & $\begin{array}{l}\text { Software Process } \\
\text { Improvement }\end{array}$ & - \\
\hline ВР026 & Software Metering & - \\
\hline
\end{tabular}




\begin{tabular}{|l|l|l|}
\hline BP027 & $\begin{array}{l}\text { Technical Software Process } \\
\text { Measurement }\end{array}$ & - \\
\hline
\end{tabular}

by SWEBOK Guide that have been (or not) followed by the small companies?

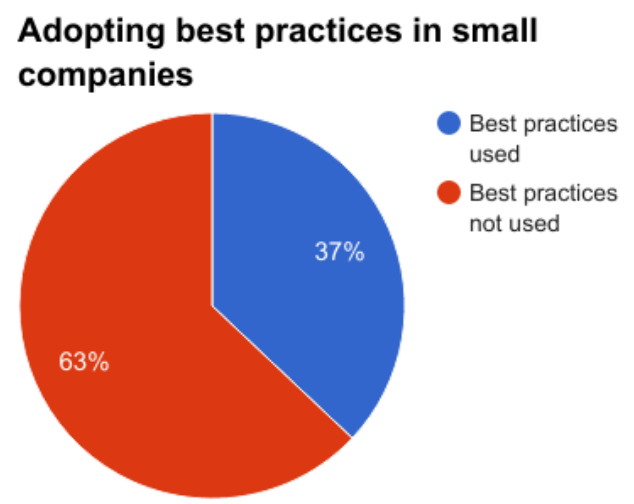

Figure 3. Adoption Scenario of Software Engineering best practices.

Despite of Table 3 demonstrates which the BP proposed by SWEBOK are used (or not) by small companies, Figure 3 also help to answer the RQ2 exposing the result found. A list of best practices not adopted by small companies and that are in accordance with the SWEBOK guide is shown in Table 3. The last column represented by the symbol "-" means that the BP was not adopted by any small company reported by the studies published by the literature during the last decade. On the other hand, the rows of the last column that contains any study ID, indicates that the BP was proposed by SWEBOK guide and followed by any small companies.

It is impressive that BP11 to BP27 were not adopted by the small companies. However, this result can be related to the company maturity level, since the major part of these BPs not adopted are related to software evolution/maintenance and software quality. These two attributes are taken into account by companies with more experience, budget, and with expert practitioners.

It is also possible to observe that the majority of SWEBOK BPs have not been adopted by small companies $(63 \%)$. This is expected since these companies have a lot of limitation related to budget, project domain, and staff size. Nevertheless, it is important to highlight that this information came from reports published in academic papers along the last decade, and case studies should be performed for corroborating this results.

RQ03: What are the reasons of the non-adoption of the software engineering best practices in small companies?

Table 4 demonstrates the reasons mentioned by small companies for why they do not adopt some of SWEBOK BPs. In the first column is indicated the reason for not adopting the best practices, and the second column represents the study ID that contains a discussion about the reason mentioned.

Table 4. Reasons why small companies do not adopt SWEBOK BPS

\begin{tabular}{|l|c|}
\hline \multicolumn{1}{|c|}{ Reason why do not adopt BPs } & Study ID \\
\hline Budget Limitation & $\begin{array}{c}\mathrm{P} 002 / \mathrm{P} 005 / \\
\mathrm{P} 011 / \mathrm{P} 013\end{array}$ \\
\hline Staff Size & $\mathrm{P} 011$ / P012 / \\
& $\mathrm{P} 015$ \\
\hline Exhaustive Project Documentation & $\mathrm{P} 005$ / P011/ \\
& $\mathrm{P} 012$ \\
\hline BPs Adoption Bureaucracy & $\mathrm{P} 017$ / P12 \\
\hline Staff Expertise & $\mathrm{P} 002$ / P001 \\
\hline Non-knowledge of BPs & $\mathrm{P} 005$ \\
\hline Short Deadline & $\mathrm{P} 012$ \\
\hline
\end{tabular}

As expected, "Budget Limitation", "Staff Size", and "Exhaustive Project Documentation" are shown as the most issues took into account by the small companies for do not adopt the BPs. It can be explained because limitation of time and money is one of the most intrinsic characteristics of small company. The small budget is an important issue because directly impact in the inadequate infrastructures, and scarce resources [12].

\section{LIMITATIONS AND THREATS TO VALIDITY}

Limitations and threats to validity can influence the result of any research. Thus, during this study, we tried to deal with them. An important issue to take into account in any exploratory study is how valid are the research's results [21]. According to Wohlin, there are four main threats to data's validity: internal, external, construct and conclusion.

This validity deals with problems that may arise due to improper research instrument designing. It means that the concept behind of what was proposed to be measured, and what is actually being measured [20] [21]. In our case, problems in the questions can lead to gather information that does not reflect the research problem's goals. A threat to construct validity was identified when we considered the SWEBOK BPs as reference of the state-of-practice. Maybe other books, papers, articles, guides, and documents related to SE can address BPs for small companies that were not considered for this work. However, we adopted the SWEBOK guide because it was developed and revised by numerous professionals from different countries who work in the area of software engineering with the objective of establishing a set of well defined criteria and norms for the professional application of the areas of knowledge of Engineering of Software.

Threats to internal validity are related to problems that can arise with the study's participants or through inappropriate research instrument designing [20] [21]. The fact of only one researcher 
carry out the 1st and 2nd studies' selection can be considered as a threat to internal validity. Nevertheless, it is important to clarify that 2 professors supervised the selection process for minimizing it. Another threat to internal validity is the using of academia's literature to build an overview of BPs adopted in industrial environment. Nevertheless, the papers published in the engines used in this work are widely accepted and followed by SE researchers and practitioners.

\section{CONCLUDING REMARKS}

This paper presented the processes carried out in a quasi-systematic mapping aimed to map the software engineering best practices already adopted for small organizations to help other companies in decision-making process about this BPs adoption. All the research process was described, consequently, other researchers can replicate/expand this study.

Thus, during the last decade small companies have been adopted 10 BPs suggested by the SWEBOK guide. The majority of BPs adopted are related to testing, using of software process model, project planning, and analysis requirements. Another information to point out is that "Budget Limitation" and "Staff Size" were reported as causes of the non-adoption of SWEBOK BPs.

Therefore, considering that they are characteristics inherent to small companies, it is necessary the building of an instrument that allows companies estimate the approximate cost for adopting each BP. Since the cost can change in each company according by the application scope, available time, team expertise, budget, and so on, a way to make easier the calculation of these cost is demanded. We believe that through the existence of this instrument, it is possible to infer more accurately the fact of adopt or not each BP.

For future work, we intend to propose a catalog of best practices suitable to small companies. In addition, we would like to perform some case studies for checking in loco the companies' reality since we would like to build the BP catalog based on the small companies' experiences.

\section{REFERENCES}

[1] Ayalew, Y. and Motlhala, K. 2014. Software Process Practices in Small Software Companies in Botswana. In 14th International Conference on Computational Science and Its Applications, Guimaraes, 49-57.

[2] Castro, R. M. and Braga, J. L. and Soares, L. S. 2013. Selection of good practices for small software development teams: a knowledge-based approach. SIGSOFT Softw. Eng. Notes 38, 6 (November 2013), 1-15.

[3] Del Maschi, V. F. and Spinola, M. M. and Costa, I. A. and Esteves, A. L. and Vendramel, W. 2007. Practical Experience in Customization of a Software Development Process for Small Companies Based on RUP Processes and MSF. In PICMET '07 - 2007 Portland International Conference on Management of Engineering \& Technology, Portland, OR, 2007, 2440-2457.

[4] Ihme, T. and Pikkarainen, M. and Teppola, S. et al. 2014. Challenges and industry practices for managing software variability in small and medium sized enterprises. Empirical Software Engineering (2014) 19: 1144. doi:10.1007/s10664013-9253-0.

[5] Iqbal, J. and Ahmad, R. B. and Nasir, M. H. and Niazi, M. Shamshirband, S. and Noor. M. A. 2016. Software SMEs' unofficial readiness for $\mathrm{CMMI}{ }^{\circledR}$-based software process improvement. Software Quality Journal 24, 4 (December 2016), 997-1023.

[6] Kalinowski, Marcos, et al. "MPS. BR: promovendo a adoção de boas práticas de engenharia de software pela indústria brasileira." XIII Congreso Iberoamericano en" Software Engineering"(CIBSE). Universidad del Azuay (in Portuguese), Cuenca, Equador, ISBN. 2010.

[7] Kitchenham, B. 2004. Procedures for performing systematic reviews. Keele University, Tech. Report.

[8] Kitchenham, B. and Charters, S. 2007. Guidelines for performing systematic literature reviews in software engineering. Software Engineering Group, School of Computer Science and Mathematics, Keele University, Tech. Report.

[9] Lars, L. 2017. Product Innovation in Small Companies: Managing Resource Scarcity Through Financial Bootstrapping. International Journal of Innovation Management, 21(2).

[10] Lester, N. G. and Wilkie, F. G. and McFall, D. and Ware, M. P. 2010. Investigating the role of CMMI with expanding company size for small- to medium-sized enterprises. J. Softw. Maint. Evol. 22, 1 (January 2010), 17-31.

[11] Monteiro, P. and Borges, P. and Machado, R. J. and Ribeiro, P. 2012. A reduced set of RUP roles to small software development teams. In International Conference on Software and System Process (ICSSP), Zurich, 2012, pp. 190-199.

[12] Moreno Junior, Valter de Assis, \& Gomes, Josir Cardoso. (2012). Benefits and success factors of open-source web services development platforms for small software houses. JISTEM - Journal of Information Systems and Technology Management, 9(3), 585-606.

[13] Niazi, M. (2012), An exploratory study of software process improvement implementation risks. J. Softw. Evol. and Proc., 24: 877-894. doi:10.1002/smr.543.

[14] Petersen, K., et al. 2008. Systematic mapping studies in software engineering. In 12th international conference on evaluation and assessment in software engineering. Vol. 17. No. 1. Sn.

[15] Sánchez-Gordón, M. L. and O’Connor, R.V. 2016. Understanding the gap between software process practices and actual practice in very small companies. Software Quality Journal. 24(3). 549-570. doi:10.1007/s11219-015-9282-6.

[16] SEI - SOFTWARE ENGENEERING INSTITUTE. "CMMI for Development, Version 1.3, CMMI-DEV v1.3, CMU/SEI Technical Report, Software Engineering Institute”, 2011.

[17] Softex (2012). MPS - Melhoria de Processo de Software e Serviços - Guia Geral MPS de Serviços (Portuguese). Brasília - DF: SOFTEX.

[18] SWEBOK Version 3.0. Guide to the Software Engineering Body of Knowledge. Available at: $<$ https://www.computer.org/web/swebok>. Acessed in: 19 apr. 2016.

[19] Thiry, Marcello, et al. 2006. Uma Abordagem para a Modelagem Colaborativa de Processos de Software em Micro e Pequenas Empresas (Portuguese). In V Simpósio Brasileiro de Qualidade de Software (SBQS), Vila Velha. 
[20] Usman M, Mendes E, Borstler J (2015) Effort estimation in agile software development: A survey on the state of the practice. In: EASE '15: Proceedings of the 19th International Conference on Evaluation and Assessment in Software Engineering.
[21] Wohlin C, Runeson P, Host M, Ohlsson MC, Bjorn R, Wessln A (2012) Experimentation in Software Engineering. SpringerVerlag. 